\title{
Impact of Oceanographic Environmental Shifts and Atmospheric Events on the Sustainable Development of Coastal Aquaculture: A Case Study of Kelp and Scallops in Southern Hokkaido, Japan
}

\author{
Yang Liu ${ }^{1, *}$, Sei-Ichi Saitoh ${ }^{1}$, Satoshi Nakada ${ }^{2}$, Xun Zhang ${ }^{1}$ and Toru Hirawake ${ }^{1}$ \\ 1 Laboratory of Marine Environment and Resource Sensing, Faculty of Fisheries Sciences, \\ Hokkaido University, 3-1-1 Minato, Hakodate, Hokkaido 041-8611, Japan; \\ E-Mails: ssaitoh@salmon.fish.hokudai.ac.jp (S.-I.S.); awesomexun@gmail.com (X.Z.); \\ hirawake@salmon.fish.hokudai.ac.jp (T.H.) \\ 2 Graduate School of Maritime Sciences, Kobe University Research Laboratory for Tsunami \\ and Marine Hazards, 5-1-1, Fukae-minami, Higashi-nada-ku, Kobe 658-0022, Japan; \\ E-Mail:snakada@maritime.kobe-u.ac.jp
}

* Author to whom correspondence should be addressed; E-Mail: yangliu315@hotmail.co.jp or yangliu315@salmon.fish.hokudai.ac.jp; Tel.: +81-13840-8843; Fax: +81-13840-8844.

Academic Editor: Phoebe Koundouri

Received: 30 September 2014 / Accepted: 15 January 2015 / Published: 26 January 2015

\begin{abstract}
We provide an overview of selected recent operational applications of satellite remote sensing and marine Geographic Information Systems (GIS) procedures to the practice of sustainable aquaculture in southern Hokkaido, Japan, focusing mainly on kelp and scallop aquaculture. We also developed a suitable aquaculture site-selection model (SASSM) for suspension culture of Gagome (a kelp species) in the same region. Models for Japanese kelp and Gagome showed that the distributions of the most suitable areas for both species overlapped. Competition between kelps was especially marked along the coastline between Hakodate and Esan. In addition, we examined the impact of oceanographic environmental changes and atmospheric events on scallop and kelp aquaculture sites, demonstrating that variations in the coastal Oyashio Current and the Tsugaru Warm Current significantly influenced the growth and harvesting seasons of scallops and kelps in Funka Bay and other sections of southern Hokkaido. Because a strong El Niño event occurred in 2010, January of that year was extremely cold. The proportion of suitable areas for both scallops and kelps during their respective growing seasons contracted in 2010. Thus, shifts in oceanographic
\end{abstract}


and atmospheric conditions should be incorporated into sustainability management planning for coastal scallop and kelp aquaculture in southern Hokkaido.

Keywords: climate events; Gagome; Japanese kelp; Japanese scallop; suitable aquaculture site-selection model (SASSM)

\section{Introduction}

Global aquaculture production has grown substantially in the past decade, reaching $66.6 \times 10^{6}$ ton in 2012. The Asia-Pacific region is dominant in this food supply sector [1]. Marine agriculture has the greatest potential for the production of safe, high quality seafood. However, with the intensification of atmospheric and oceanographic environmental changes, more attention is now being focused on the sustainability of aquaculture; changing environments threaten food security and economic growth [2]. The suspension culture method used for Japanese scallop (Mizuhopecten yessoensis) aquaculture is largely concentrated in Funka Bay, Japan, where it has a key economic role for coastal communities. The production of Japanese scallop in Hokkaido amounted to 418,175 ton in 2012 [3]. In addition, two species of seaweeds, Japanese kelp (Saccharina japonica) and Gagome (S. sculpera), are commercially harvested in the waters of southern Hokkaido; in 2012, harvests of the two species amounted to 5504 ton and 315.2 ton, respectively [3]. Japanese kelp is a preferred source of kombu, but Gagome has been invading S. japonica habitat [4], causing serious industrial problems. Gagome is usually considered a pest species, but this view is changing. The use of brown algae as medicines and health foods has been growing in recent years because these marine plants contain several important carbohydrates, including alginate, fucoidan, and laminarin [5]. Many new commodities have been developed from Gagome, and demand for this kelp has been growing. However, the recent production of kelp and scallops has been highly variable. The root causes of this variability may lie in human activities that have resulted in atmospheric and oceanographic environmental changes [6].

The Japanese scallop is a cold-tolerant shellfish that inhabits waters that have wide seasonal shifts in temperature $\left(5-20^{\circ} \mathrm{C}\right)$ [7]. The two commercial kelps are also temperate/cold-water species. When the seawater temperature exceeds $23^{\circ} \mathrm{C}$, kelp blades die back toward the meristem [8]. Consequently, both scallop and kelp aquaculture production facilities are vulnerable to oceanographic environmental changes, especially shifts in water temperature.

Funka Bay and the remaining sections of southern Hokkaido provide unusually favorable marine environmental conditions for aquaculture activities. The region is affected by the coastal Oyashio Current (COC) and the Tsugaru Warm Current (TWC). The COC brings cold, low-salinity, high-nutrient water that sometimes flows into Funka Bay in winter and spring. The TWC is an eastward-flowing branch of the northward-flowing Tsushima Current. The TWC flows through the Tsugaru Strait and into Funka Bay from mid-July; its waters are warm and highly saline $[9,10]$. In recent years, the southward intrusion of the Oyashio has been highly variable between seasons and years [11]. In addition, the TWC flow has varied seasonally, corresponding with seasonal changes in sea level differences between the Japan Sea and Pacific Ocean sides of the Tsugaru Strait [12]. Climate change-associated spatial and temporal fluctuations in the COC and TWC have potentially significant influences on scallop and kelp aquaculture 
along the coast of southern Hokkaido. Particularly extreme weather conditions, such as a strong El Niño event, occurred in the period 2009-2010. Many studies have shown that the ENSO (El Niño/La Niña Southern Oscillation) has considerable influence on the inter-annual variability in environmental conditions within tropical Pacific regions; the ENSO also affects northeastern Asia [13-15]. In the winter of 2010, East Asia, Europe, and North America suffered extreme cold events under the influence of the Arctic Oscillation (AO) [16].

Satellite remote sensing technology and Geographical Information System (GIS) procedures have proven to be especially important in acquiring spatial and temporal data for effective resource management; they may also be applied to coastal environment monitoring and management [17]. Based on an understanding of the interaction between aquaculture and the environment, an informed site selection process is likely to be crucial for the sustained development of aquaculture. Our previous work has developed suitable aquaculture site-selection models (SASSMs) for the identification of suitable locations for Japanese kelp and Japanese scallop aquaculture [18-22]. We have now developed SASSMs to identify the most suitable areas for Gagome aquaculture and to examine the potential impacts of oceanographic environmental changes and atmospheric events on the development of scallop and kelp aquaculture in Funka Bay and the remainder of southern Hokkaido.

\section{Methods}

\subsection{Study Area}

The study area comprised the coastal waters of southern Hokkaido, including Funka Bay and the Tsugaru Strait. This area lies between $41^{\circ} 40^{\prime} \mathrm{N}$ and $42^{\circ} 10^{\prime} \mathrm{N}$, and $140^{\circ} 40^{\prime} \mathrm{E}$ and $141^{\circ} 10^{\prime} \mathrm{E}$. Mean and maximum water depths are $38 \mathrm{~m}$ and $107 \mathrm{~m}$, respectively. Japanese kelp and Gagome are farmed along the coastline from Shikabe to Hakodate in southern Hokkaido; most Japanese scallops are farmed in Funka Bay (Figure 1).

\subsection{Satellite Data}

The data used included sea surface temperature (SST), Chl- $a$ concentration, sea surface nitrate concentration (SSN), and suspended solids concentration (SS). The parameters we used were Level-2 data (at $1-\mathrm{km}$ resolution) derived from measurements made by a Moderate Resolution Imaging Spectroradiometer (MODIS) on board the Earth Observing System Aqua satellite. We used the R2012.0 version of daily data from January 2003 to May 2014. Monthly averages of nLw (555) images were used to calculate SS images with the algorithm of Ahn et al. [23]. SSNs were calculated using the algorithm of Liu et al. [21]. Advanced Land Observing Satellite (ALOS) Advanced Visible and Near-Infrared Radiometer Type-2 (AVNIR-2) images with 10-m resolution were used for extracting social-infrastructural and constraint data, such as harbors, town/industrial areas, and river mouths. Bathymetry data were obtained from the Japan Oceanographic Data Center (JODC) and were integrated and gridded at 150-m intervals. All of the remotely-sensed data were processed with the SeaWiFS Data Analysis System (SeaDAS) 6.4, ERDAS Imagine 2010, and ArcGIS 10.0 software. 


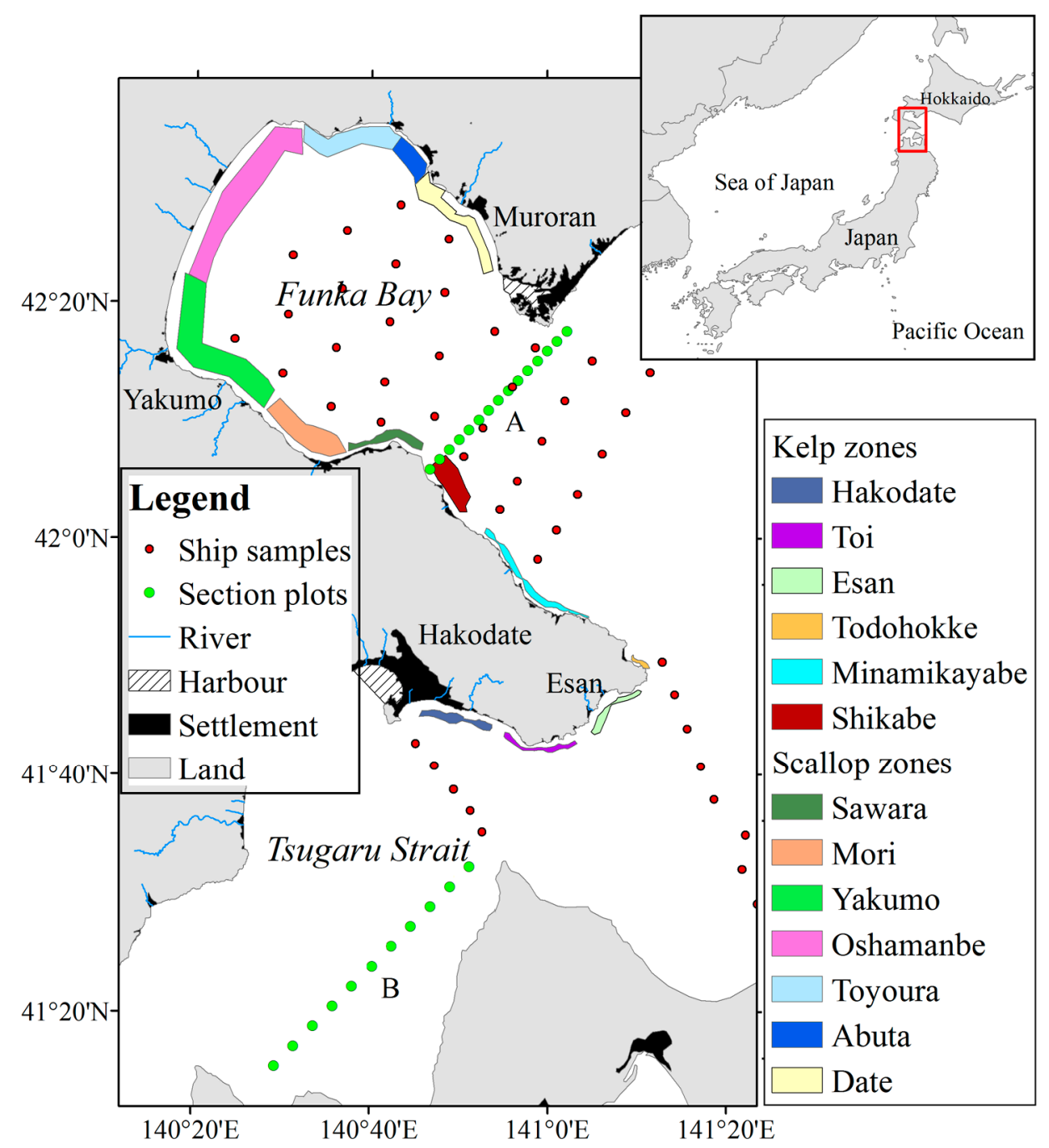

Figure 1. Study area showing scallop and kelp aquaculture zones and water temperature cross-section lines and ship samples location in southern Hokkaido, Japan.

\section{3. $4 D-V A R$ Data}

A spatiotemporally high-resolution output was produced for Funka Bay using a land-sea coupled model [24] that has been available since 23 January 2008. The coupled model contains a 3D ocean general circulation model that was developed at Kyoto University [25]. The components of the output from the model are temperature, salinity, 3D velocity, seawater density, and sea level. The four dimensional-variational (4D-VAR) data assimilation system uses a nesting method (NEST2) with a finest horizontal resolution of $1 / 54^{\circ}$ longitude and $1 / 72^{\circ}$ latitude to reproduce small-scale physical features within coastal zones. For our modeling exercise, we used simulated temperatures for Funka Bay (between January 2008 and December 2013) at depths ranging from $2 \mathrm{~m}$ near the sea surface to $150 \mathrm{~m}$ at a vertical resolution of $4 \mathrm{~m}$ and a time resolution of $24 \mathrm{~h}$.

\subsection{Ship Samples Data}

Shipboard data were obtained during 15 cruises on the TS "Oshoro-Maru" and RV "Ushio-Maru" (Hokkaido University) between April 2010 and January 2012. Optical measurements, 
conductivity-temperature-depth (CTD) measurements, and water sampling were conducted at 33 stations in Funka Bay and 14 stations in the Tsugaru Strait (Figure 1). Water temperature data was conducted vertically to a depth of $50 \mathrm{~m}$.

\subsection{Procedures for Sea Temperature-Depth Visualizations}

Daily vertical water column distributions of sea temperature were extracted using the 4D-VAR data assimilation system. We obtained vertical data corresponding to latitude/longitude locations of the study areas in order to ascertain marine environmental conditions for scallop and kelps. Daily sea temperature-depth structures along point cross-section lines located at the entrance of Funka Bay (A) and the middle of Tsugaru Strait (B) (Figure 1) were visualized using Ocean Data View 4 (ODV 4) software.

\subsection{Suitable Aquaculture Site Selection Models (SASSMs)}

The SASSMs used here were built using hierarchical structures (Figure 2). Each model incorporated an environment sub-model (SST, Chl-a, SS, and Bathymetry), a socio-infrastructure sub-model (distance to town, distance to pier, and distance to land-based facilities) and a constraint sub-model (harbor, river mouth, and industrial areas) matching the basic requirements for scallop aquaculture in Funka Bay [18]. We added nutrient parameters (SSN) and slope to develop a more accurate SASSM for Japanese kelp [21], and used the models to develop a SASSM for Gagome. Suitability scores for each parameter were defined according to the requirements of Gagome aquaculture using the suspension technique (Table 1). Suitability scores for each criterion were ranked on a scale from 1 (least suitable) to 8 (most suitable); the scoring system for Gagome followed Liu et al. [21]. Gagome occurs in deeper waters than Japanese kelp [26]. Therefore, we set a depth score of 8 at 15-30 m for the Gagome bathymetry parameter. The highest depth score for Japanese kelp was $5 \mathrm{~m}$ shallower. These depths are at the limits of aquaculture construction capability in waters $60 \mathrm{~m}$ deep.

Table 1. Physical factor requirements and suitability scores for Gagome aquaculture-site selection in southern Hokkaido, Japan.

\begin{tabular}{|c|c|c|c|c|c|c|c|c|}
\hline \multicolumn{9}{|c|}{ Suitability Rating and Score } \\
\hline Parameter & 1 & 2 & 3 & 4 & 5 & 6 & 7 & 8 \\
\hline Sea surface & $<4$ & $4-4.5$ & $4.5-5$ & $5-5.5$ & $5.5-6$ & $6-6.5$ & $6.5-7$ & 70 \\
\hline temperature $\left({ }^{\circ} \mathrm{C}\right)$ & $>17.5$ & $16-17.5$ & $14.5-16$ & $13-14.5$ & $11.5-13$ & $10.5-11.5$ & $9-10.5$ & $7-9$ \\
\hline \multirow{2}{*}{ Bathymetry (m) } & $0-2.1$ & $2.1-4.3$ & $4.3-6.4$ & $6.4-8.6$ & $8.6-10.7$ & $10.7-12.9$ & $12.9-15$ & \multirow{2}{*}{$15-30$} \\
\hline & $>60$ & $55-60$ & $50-55$ & $45-50$ & $40-45$ & $35-40$ & $30-35$ & \\
\hline $\begin{array}{c}\text { Secchi disk } \\
\text { depth }\left(\mathrm{g} \cdot \mathrm{m}^{-3}\right)\end{array}$ & $0-0.5$ & $0.5-1$ & $1-1.5$ & $1.5-2$ & $2-2.5$ & $2.5-3$ & $3-3.5$ & $>3.5$ \\
\hline $\begin{array}{l}\text { Sea surface } \\
\text { nitrate }(\mu \mathrm{M})\end{array}$ & $<0.64$ & $0.64-1.49$ & $1.49-2.69$ & $2.69-4.48$ & $4.48-7.47$ & $7.47-13.44$ & $13.44-31.36$ & $>31.36$ \\
\hline Slope $\left(^{\circ}\right)$ & $<5$ & $5-10$ & $10-15$ & $15-18$ & $18-20$ & $20-23$ & $23-25$ & $>25$ \\
\hline
\end{tabular}




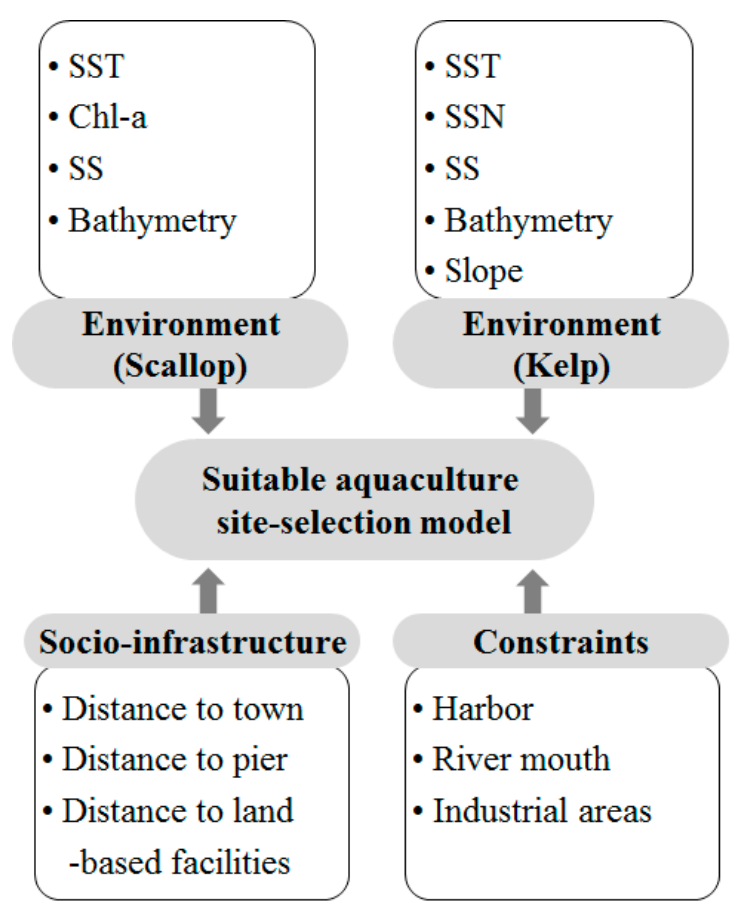

Figure 2. Hierarchical schematic of the suitable aquaculture site selection models (SASSMs). SST, sea surface temperature; SS, suspended solid concentration; SSN, sea surface nitrate concentration.

We set a SST score of 8 at $7-9{ }^{\circ} \mathrm{C}$ for Gagome and $10-11^{\circ} \mathrm{C}$ for Japanese kelp because (i) the growth periods of the two species differ, from May to July for Japanese kelp and from April to June for Gagome, and (ii) Gagome inhabits deeper, cooler waters than Japanese kelp.

Suitability scores for SSN parameters were defined according to the Michaelis-Menten kinetic relationship between nitrate uptake and nitrate concentration for disks cut from kelp blades. Nitrate kinetics were described by the half-saturation concentration $\left(\mathrm{K}_{\mathrm{m}}\right)$ and the maximum uptake rate $\left(\mathrm{V}_{\max }\right)$. Thus, for $S$. sculpera disks, $\mathrm{K}_{\mathrm{m}}=4.48 \mu \mathrm{M}$ and $\mathrm{V}_{\max }=0.92 \mu \mathrm{g} \mathrm{N} / \mathrm{cm}^{2} / \mathrm{h}[27,28]$. $\mathrm{NO}_{3}{ }^{-}$concentrations were placed in rank order from 1 (least suitable) to 8 (most suitable) by calculations based on nitrate uptake rates of $0.115 \mu \mathrm{g} \mathrm{N} / \mathrm{cm}^{2} / \mathrm{h}$ (Table 1$)$.

The scores for SS and the slope parameter were same identical for the two kelp species.

We used a pairwise comparison method in an analytic hierarchy process (AHP) to develop a weighting for each criterion. Relative importance was obtained from published literature data and the opinions of experts [21]. Each model was implemented using the Model Builder package in ArcGIS. The construction was based on a multi-criteria evaluation (MCE: weighted linear combination) procedure. Final suitability maps were created by combining these models.

\section{Results and Discussion}

\subsection{Verification of $4 D-V A R$ Data}

For water temperature data, we compared 4D-VAR data and shipboard data at all water depth of 6,10 , and $14 \mathrm{~m}$. The results showed a strong relationship between 4D-VAR and shipboard water 
temperature, with $R^{2}$ values of 0.94 (Figure 3). The 4D-VAR data provided reasonable temperature values in this study.

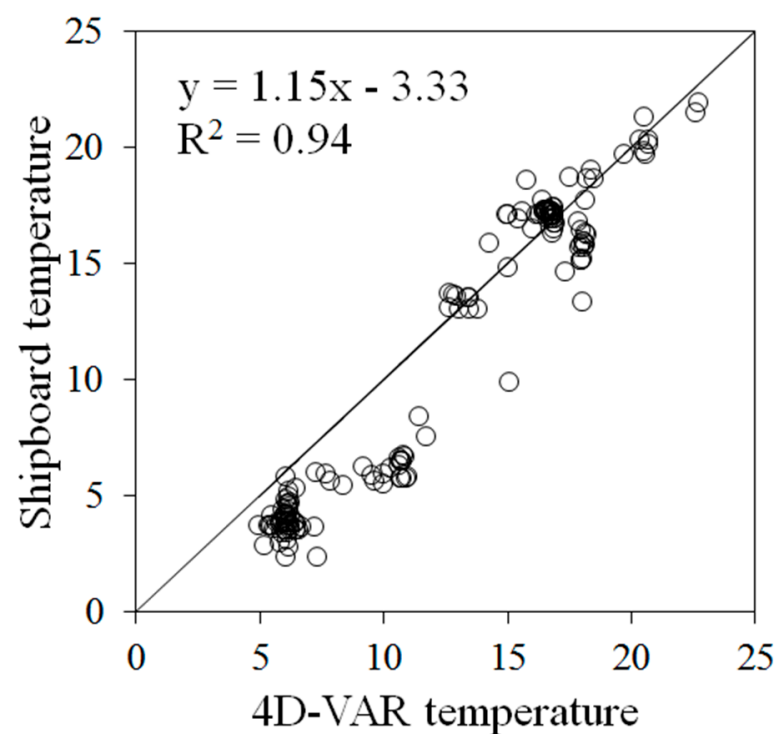

Figure 3. Comparisons of shipboard data with four dimensional-variational (4D-VAR) temperature data in Southern Hokkaido during observations from April 2010 to January 2012.

\subsection{Sea Temperature-Depth Visualizations}

The COC began to affect Funka Bay in February and the scallop harvest began in the March-April period. Thus, we generated water temperature section maps for the entrance of Funka Bay from the 4D-VAR dataset for each 10-day interval from February to March in 2008, 2009, 2010, 2011, 2012, and 2013 (Figure 4). We observed vertical water temperature variations among different years. Oyashio cold water strongly affected Funka Bay from the end of March in 2008. From the daily vertical water temperature variations, we determined that the current entered the bay earlier than March in 2011, 2012, and 2013. However, the current did not enter the bay in 2009; it arrived late in 2010 and had only weak effects on the bay's temperature structure.

The TWC affected southern Hokkaido and Funka Bay in summer and autumn; Gagome was harvested from June to July. Therefore, we generated water temperature section maps for the middle of the Tsugaru Strait for 10-day intervals in the June-July period of each year (Figure 5). Warm water arrived in early July in 2010 and 2013, when the surface waters were warmer than in other years. These variations are associated with the coupling of oceanic variability and atmospheric circulation (as in ENSO event) $[10,12,29]$. Variations in the COC and TWC may significantly influence marine environmental conditions in the aquaculture region. 


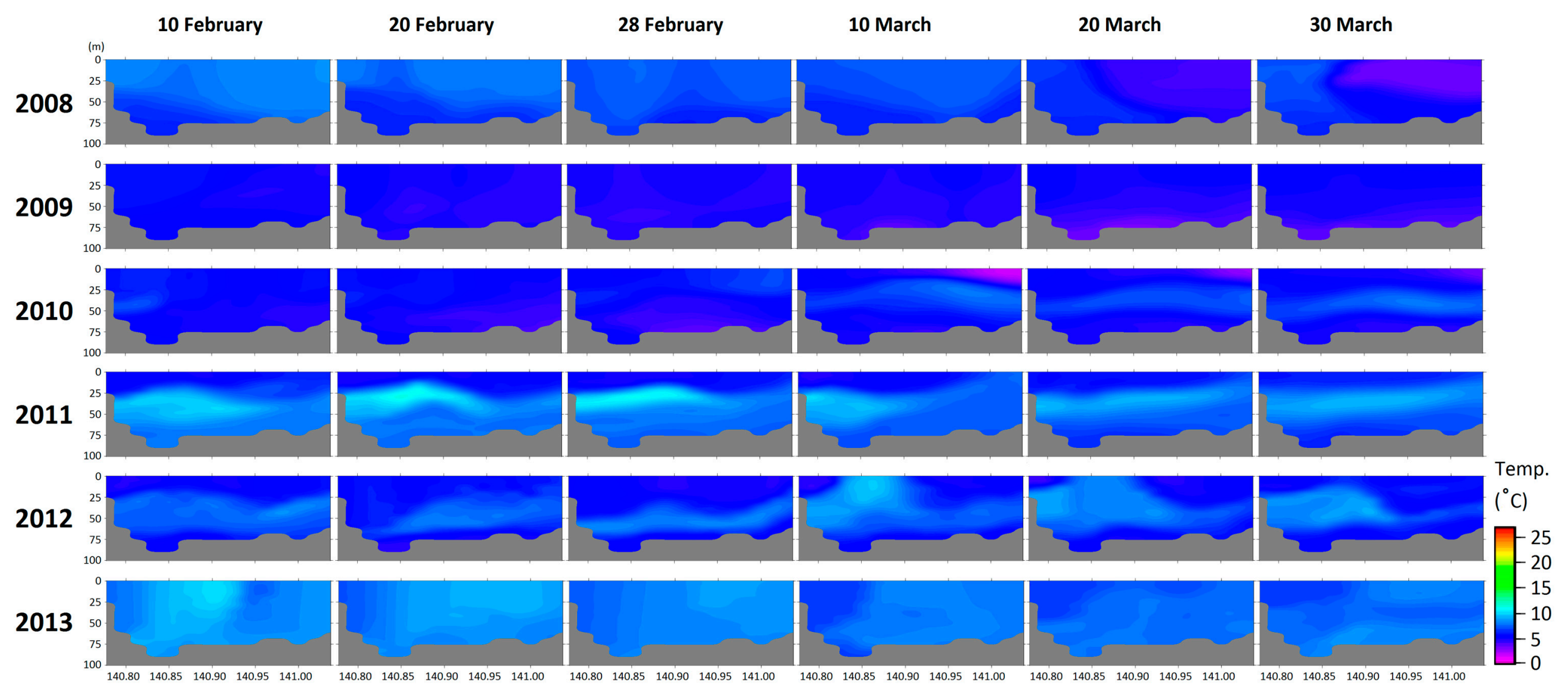

Figure 4. Vertical distribution of sea temperature at the entrance to Funka Bay during 10-day intervals in the February-March period from 2008 to 2013. 


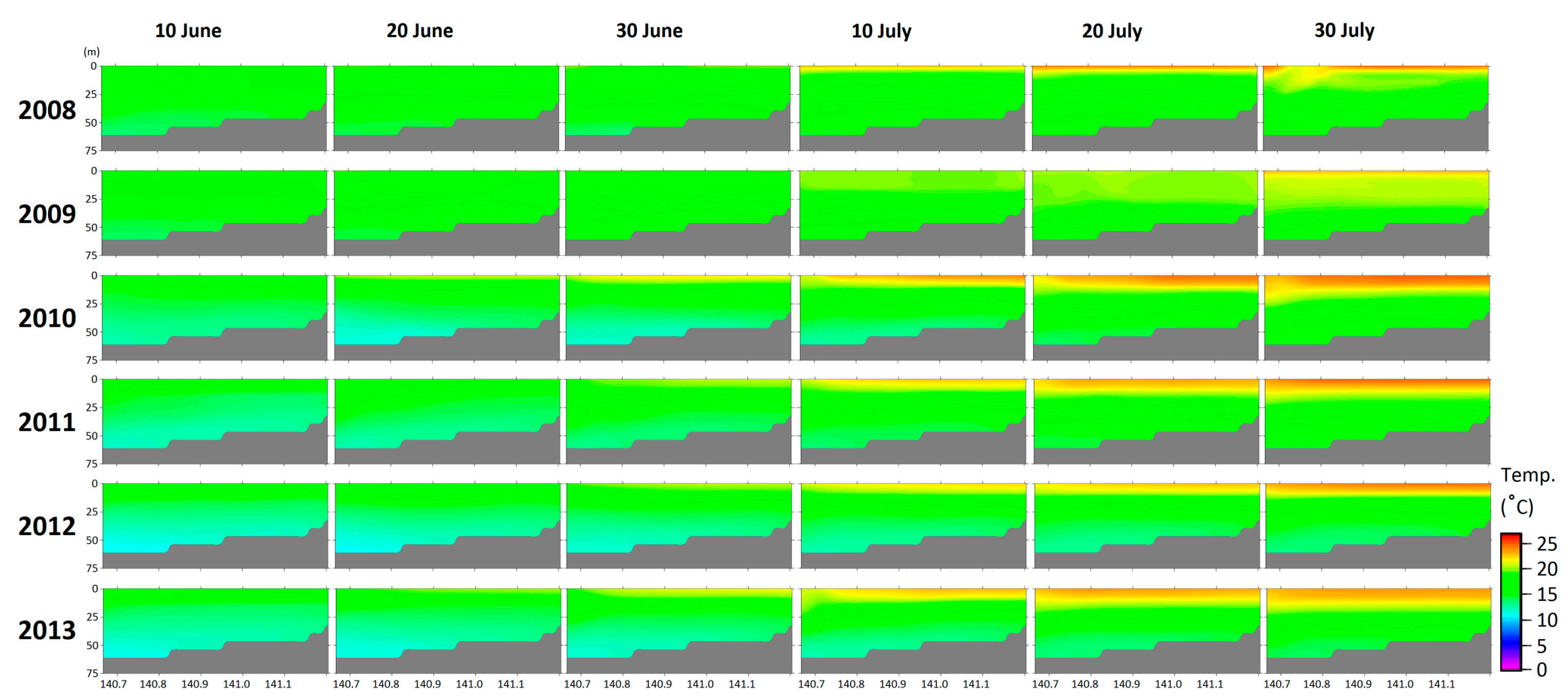

Figure 5. Vertical distribution of sea temperature in the middle of Tsugaru Strait during 10-day intervals in the June-July period from 2008 to 2013. 


\subsection{Impact of Oceanographic Environment Changes on SASSMs}

Using our SASSMs, we generated monthly suitable site selection maps for Japanese scallop in the Funka Bay coastal region during the month of March for the period 2008-2013 (Figure 6). March conditions were most suitable in 2008 and worst in 2010. The SASSM maps were validated by the location of existing Japanese scallop culture operation (see Figure 1). The suitable areas for Japanese scallop model output were matched with existing scallop aquaculture location (Figure 6). Combining this information with data in the water temperature section maps for February and March, we ascertained that the COC strongly affected Funka Bay in spring 2008, when large volumes of high-nutrient water entered the bay and generated conditions conducive to the growth of scallops. Evidence obtained from two different datasets (satellite and 4D-VAR) was strongly corroborative. Figure 4 shows that the COC slightly affected Funka Bay in 2010, but a strong El Niño event occurred in winter 2010 and January 2010 was extremely cold, thereby reducing the extent of the most suitable areas in March 2010. This finding is corroborated by a previous study [22]. Therefore, suspension culture in the $0-20 \mathrm{~m}$ depth range was influenced not only by oceanographic environmental changes, but also by shifts in climate.

Using our SASSMs, we generated suitable site selection maps for Gagome in southern Hokkaido for the month of July during the period from 2008 to 2013 (Figure 7). The SASSM maps were also validated by the location of existing Gagome culture operation in Minamikayabe, Toi and Hakodate (see Figure 1). The most of suitable areas (scores 7 and 8) for Gagome model output were matched with existing Gagome aquaculture location (Figure 7). The proportion of the most suitable areas was smaller in 2010 and 2013 than in other years. Water temperature section maps for the Tsugaru Strait during the June-July period (Figure 5) indicate that warm water inflow significantly increased at the surface during 2010 and 2013. This inflow may have influenced the southern Hokkaido coastal region. Since Gagome blades die back at temperatures $\geq 23{ }^{\circ} \mathrm{C}$ and this kelp is harvested from June to July, shifts in TWC water temperature during July are of particular concern.
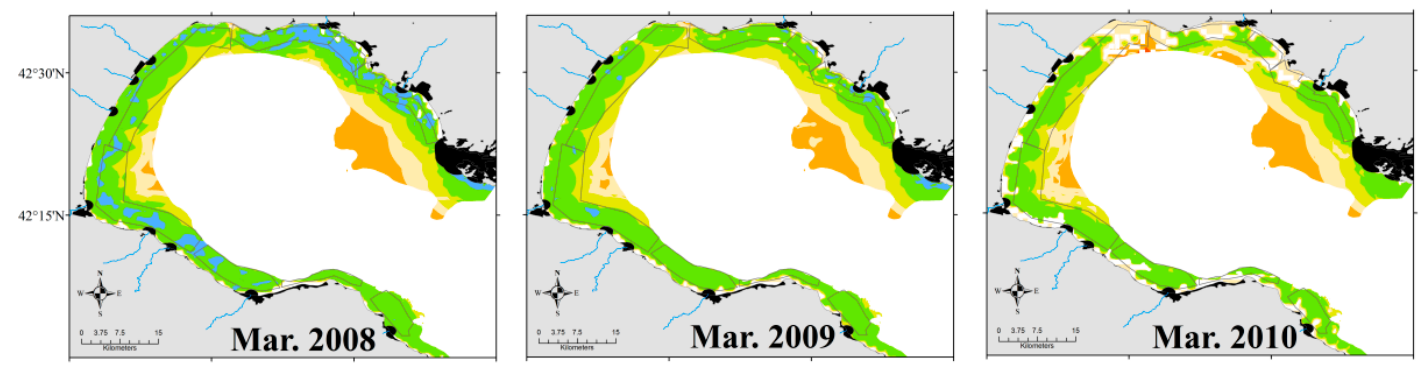

Legend

- Constraint

- 1 [Least Suitable]
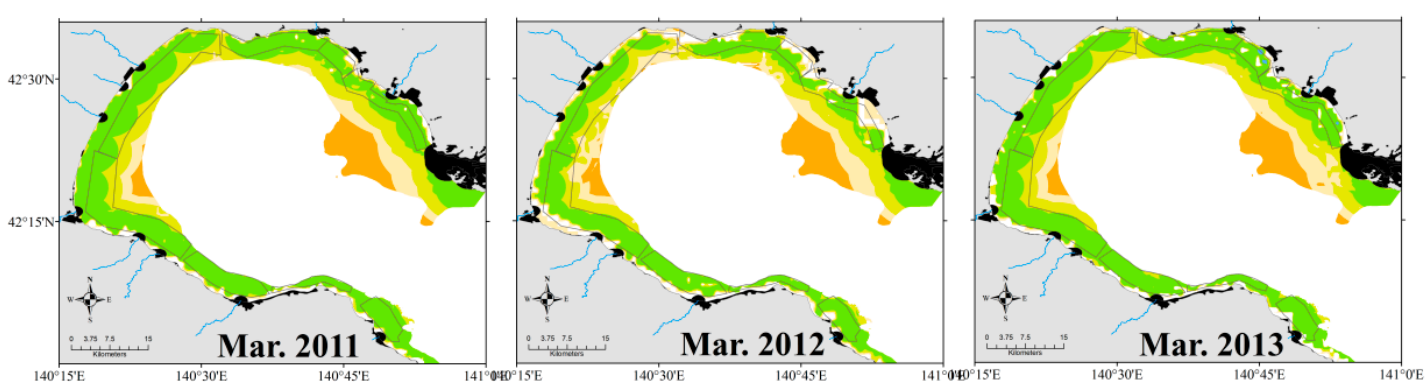

2

$-3$

4

5

$-6$

$-7$

- 8 [Most suitable]

River

- Settlement

प्याa Harbour

Land

$\square$ Aquaculture zone

Figure 6. Suitable aquaculture site selection model (SASSM) maps for Japanese scallop during the month of March (2008-2013) in Funka Bay, Japan. 


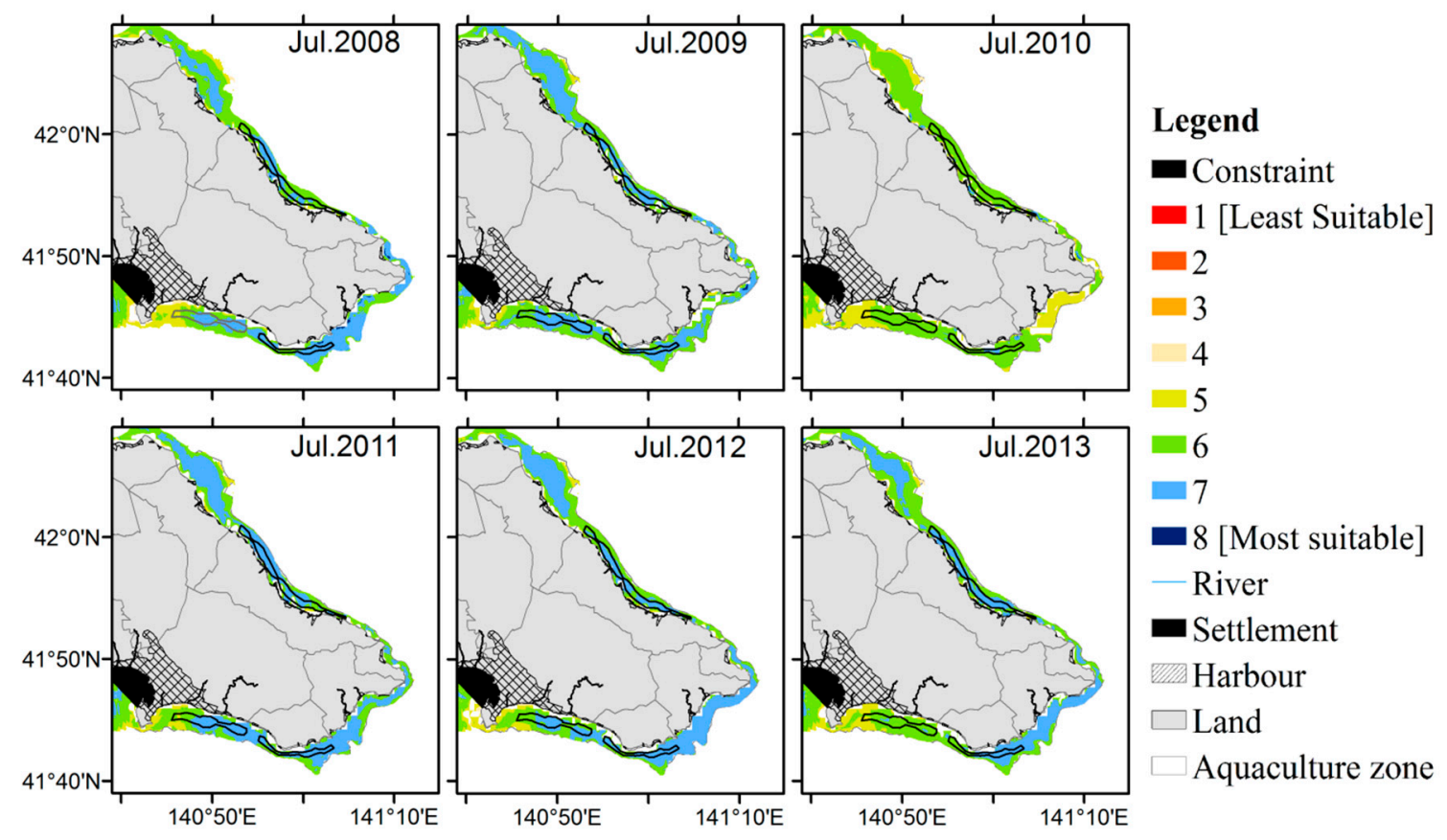

Figure 7. Suitable aquaculture site selection model (SASSM) maps for Gagome during the month of July (2008-2013) in southern Hokkaido.

\subsection{Impact of Climate Events on SASSM Models}

Because of the strong El Niño event in 2010 and the extreme cold period in January of that year [22], we generated final SASSM maps for the growing periods of each species in 2009 and 2010 to illustrate effects related to climate changes (Figure 8). The SASSM maps were validated by the location of existing Japanese scallop, Japanese kelp and Gagome culture operation (see Figure 1). The most of suitable areas (scores 7 and 8) for each species model output were matched with existing aquaculture location (Figure 8).

Conditions during the growing period for Japanese scallop in 2009 (Figure 8A) were obviously better than during the same season in 2010 (Figure 8B). We combined production data to evaluate the areas of different suitability levels for each Japanese scallop aquaculture zone in Funka Bay (Table 2). We found that suitable sites for scallop aquaculture changed considerably relative to different years, with the percentage of the most suitable areas (scores 7 and 8) being significantly lower in climate event years (2010) than the normal year (2009) (Table 2). Especially in 2010, the most suitable areas (score 8) decreased to $0 \%$ in all the aquaculture zones. This finding is corroborated by a previous study [22] and also was verified by Japanese scallop production statistics for each aquaculture zones in Funka Bay (Table 2). The productions of Japanese scallop in the aquaculture zones (Date, Abuta, Toyoura, Oshamambe, Yakumo, Mori and Sawara), which were all inside Funka Bay showed a decreasing trend in 2010 .

The proportion of the most suitable areas for Japanese kelp during the growing season declined from 2009 (Figure 8C) to 2010 (Figure 8D), but except Esan, which the most suitable areas (score 8) increased from $4.9 \%$ in 2009 to $10.3 \%$ in 2010 (Table 2). This phenomenon may be influenced by a shift that is attributable to ENSO events and variations of TWC, as indicated by previous work [21]. The changes of most suitable areas for Japanese kelp were also reflected in the production statistics of each aquaculture 
zone. The total production of Japanese kelp in Shikabe, Minamikayabe, Todohokke, Toi and Hakodate decreased in 2010, but only the Esan zone had an increase in 2010 (Table 2).

Table 2. Different suitability levels (expressed as a percentage of the total aquaculture area) of each aquaculture zone for Japanese scallops (September-December), for Japanese kelp (May-July) and Gagome (March-May) between the normal year (2009) and climate event year (2010) in southern Hokkaido. Location of each zone was shown in Figure 1.

\begin{tabular}{|c|c|c|c|c|c|c|c|c|c|}
\hline \multirow{2}{*}{ Species } & \multirow{2}{*}{ Year } & \multirow{2}{*}{ Zone } & \multirow{2}{*}{$\operatorname{Area}\left(\mathbf{k m}^{2}\right)$} & \multicolumn{5}{|c|}{ Suitability scores } & \multirow{2}{*}{$\begin{array}{l}\text { Production } \\
\text { (tons) }\end{array}$} \\
\hline & & & & 4 & 5 & 6 & 7 & 8 & \\
\hline \multirow{14}{*}{$\begin{array}{c}\text { Japanese } \\
\text { scallop }\end{array}$} & \multirow{7}{*}{2009} & Date & 28.6 & 0.1 & 1.1 & 7.5 & 78.8 & 12.5 & 4724 \\
\hline & & Abuta & 16.8 & 0.0 & 0.2 & 7.1 & 86.5 & 6.2 & 7409 \\
\hline & & Toyoura & 37.7 & 0.3 & 0.9 & 10.5 & 79.4 & 8.8 & 12,310 \\
\hline & & Oshamambe & 98.7 & 0.0 & 0.7 & 10.7 & 64.4 & 24.2 & 21,360 \\
\hline & & Yakumo & 98.4 & 0.0 & 0.0 & 11.0 & 68.8 & 20.1 & 35,551 \\
\hline & & Mori & 44.2 & 0.0 & 0.0 & 0.6 & 98.1 & 1.3 & 19,684 \\
\hline & & Sawara & 11.7 & 0.0 & 0.0 & 5.5 & 76.2 & 18.3 & 9754 \\
\hline & \multirow{7}{*}{2010} & Date & 28.6 & 0.7 & 4.6 & 51.3 & 43.3 & 0.0 & 2997 \\
\hline & & Abuta & 16.8 & 0.2 & 1.3 & 64.8 & 33.6 & 0.0 & 4452 \\
\hline & & Toyoura & 37.7 & 0.4 & 1.8 & 18.8 & 79.0 & 0.0 & 8516 \\
\hline & & Oshamambe & 98.7 & 0.1 & 2.3 & 38.8 & 58.8 & 0.0 & 15,550 \\
\hline & & Yakumo & 98.4 & 0.0 & 3.7 & 46.4 & 49.9 & 0.0 & 25,960 \\
\hline & & Mori & 44.2 & 0.2 & 0.2 & 54.6 & 45.0 & 0.0 & 16,623 \\
\hline & & Sawara & 11.7 & 0.9 & 1.9 & 25.8 & 71.4 & 0.0 & 10,235 \\
\hline \multirow{12}{*}{$\begin{array}{c}\text { Japanese } \\
\text { kelp }\end{array}$} & \multirow{6}{*}{2009} & Shikabe & 24.5 & 0.0 & 0.1 & 7.5 & 77.3 & 15.1 & 415 \\
\hline & & Minamikayabe & 16.3 & 0.0 & 0.6 & 18.8 & 71.1 & 9.6 & 3580 \\
\hline & & Todohokke & 1.1 & 0.3 & 19.6 & 29.0 & 49.5 & 1.6 & 119 \\
\hline & & Esan & 8.4 & 0.2 & 2.8 & 22.0 & 70.1 & 4.9 & 582 \\
\hline & & Toi & 7.3 & 0.0 & 0.0 & 0.0 & 45.6 & 54.4 & 677 \\
\hline & & Hakodate & 12.2 & 0.0 & 0.0 & 0.0 & 74.5 & 25.5 & 489 \\
\hline & \multirow{6}{*}{2010} & Shikabe & 24.5 & 0.0 & 0.0 & 11.0 & 88.9 & 0.0 & 335 \\
\hline & & Minamikayabe & 16.3 & 0.0 & 0.0 & 9.0 & 90.2 & 0.8 & 3478 \\
\hline & & Todohokke & 1.1 & 0.0 & 0.0 & 19.0 & 81.0 & 0.0 & 82 \\
\hline & & Esan & 8.4 & 0.0 & 0.0 & 0.0 & 89.7 & 10.3 & 642 \\
\hline & & Toi & 7.3 & 0.0 & 0.0 & 10.3 & 57.7 & 32.0 & 599 \\
\hline & & Hakodate & 12.2 & 0.0 & 0.0 & 22.3 & 77.7 & 0.0 & 295 \\
\hline \multirow{6}{*}{ Gagome } & \multirow{3}{*}{2009} & Minamikayabe & 16.3 & 0.0 & 0.2 & 31.5 & 66.3 & 2.0 & 156.7 \\
\hline & & Toi & 7.3 & 0.0 & 0.0 & 0.0 & 45.6 & 54.4 & 0.2 \\
\hline & & Hakodate & 12.2 & 0.0 & 0.0 & 0.0 & 50.8 & 49.2 & 0.3 \\
\hline & \multirow{3}{*}{2010} & Minamikayabe & 16.3 & 0.0 & 4.9 & 64.2 & 30.8 & 0.0 & 30.6 \\
\hline & & Toi & 7.3 & 0.0 & 0.0 & 45.5 & 52.4 & 2.1 & 0 \\
\hline & & Hakodate & 12.2 & 0.0 & 0.0 & 0.0 & 83.6 & 16.4 & 0.3 \\
\hline
\end{tabular}

Production data from Marine Net Hokkaido [3].

The proportion of most suitable areas (scores 7 and 8) for Gagome during the growing period (March to May) also declined from 42\% in 2009 (Figure 8E) to 27\% in 2010 (Figure 8F). The changes of most suitable areas for Gagome were also reflected in the production statistics of each aquaculture 
zone. In 2009, the total production of Gagome aquaculture in Minamikayabe, Toi and Hakodate were 156.7, 0.2 and 0.3 tons, respectively. However, in 2010, the production of Gagome in Minamikayabe and Toi decreased into 30.6 and 0 tons, respectively, and no change was recorded in Hakodate. The total most suitable areas (scores 7 and 8) for Gagome in Hakdate were no change (Table 2). These changes were also reflected by SASSM maps (see Figure 8E,F), where the most suitable areas in Minamikayabe and Toi were showed a deceasing trend in 2010, but remained unchanged in Hakodate zones.
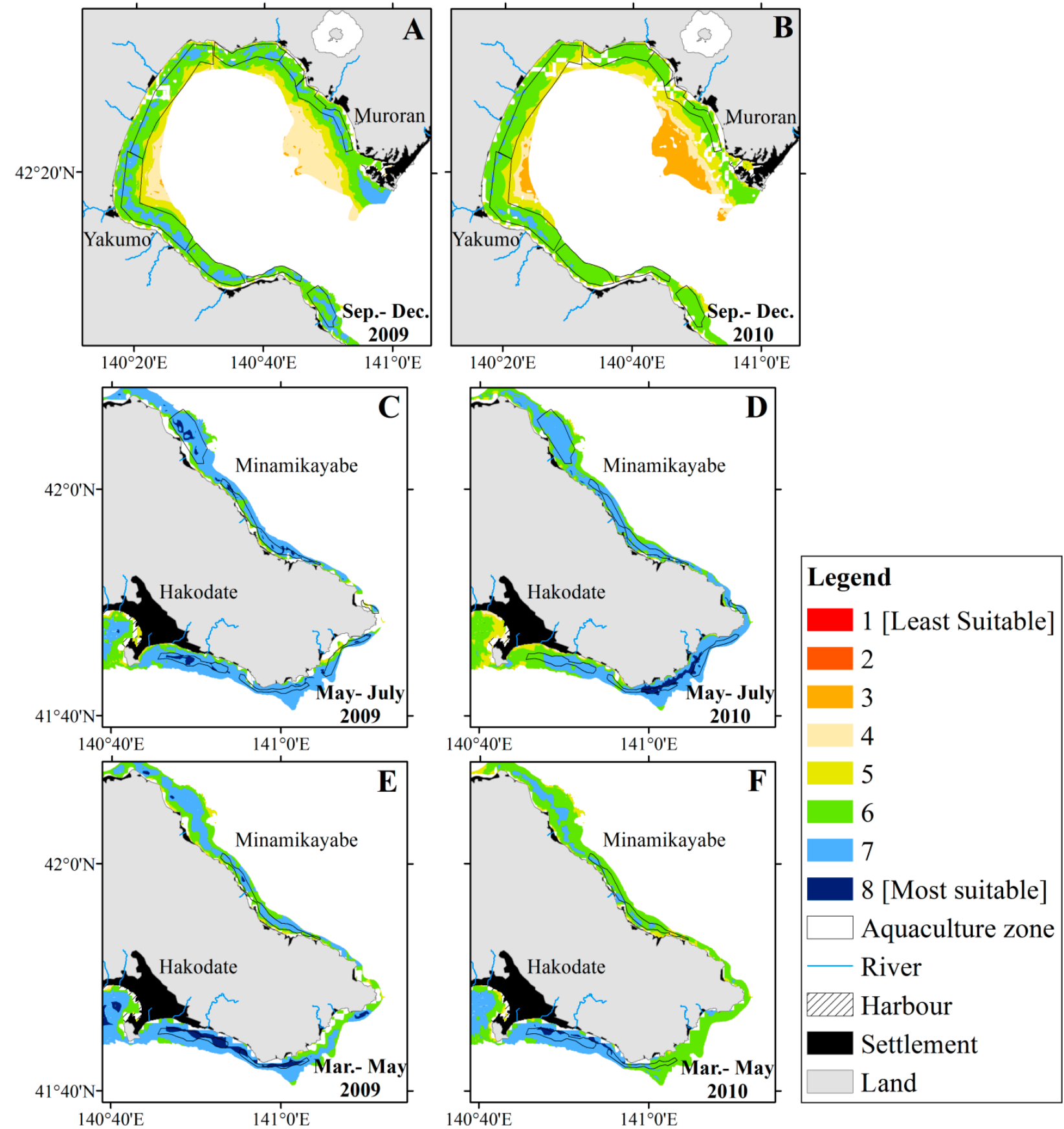

Figure 8. Growing season suitability site maps for Japanese scallop (September-December) in 2009 (A) and 2010 (B); for Japanese kelp (May-July) in 2009 (C) and 2010 (D); and for Gagome (March-May) in 2009 (E) and 2010 (F). 
The SASSM distribution maps show that most of the suitable areas for Japanese scallop aquaculture had scores greater than 5. Most of the suitable areas for Japanese kelp and Gagome (scores of 7 and 8) covered about $70 \%$ of the potential area along the coastline of the southern Hokkaido. However, regions that have not been producing Gagome may also be suitable for aquaculture, with the avoidance of competing with Japanese kelp. Highly suitable areas for Japanese scallop, Japanese kelp and Gagome occur in the Yakumo, Minamikayabe and Hakodate regions, respectively. These regions support extensive aquaculture farm operations for these species. Models for Japanese kelp and Gagome showed that the distributions of the most suitable areas (scores of 7 and 8) were similar. Competition between the kelp species is especially marked along the coastline between Hakodate and Esan. Comparing the production of Japanese kelp and Gagome in the normal year (2009) and climate event year (2010), we could see the production of Japanese kelp with slight changes in Minamikayabe, but with large decreases in Hakodate. Meanwhile, the production of Gagome was the opposite of Japanese kelp (Table 2). These findings should be taken into account in future Japanese kelp and Gagome farming management plans.

The environmental shifts that we detected were associated with large-scale variability in conditions in the northwestern Pacific that were related to ENSO events [21,22,30]. Thus, climate change-associated spatial and temporal fluctuations in the COC and TWC should be incorporated into kelp and scallop aquaculture planning along the coast of Funka Bay and other regions of southern Hokkaido.

\section{Conclusions}

Our integration of satellite remote sensing information with GIS will contribute significantly to the sustainable development of aquaculture. Our enhanced SASSMs effectively identified the most suitable areas for Gagome aquaculture in southern Hokkaido and demonstrated that Japanese kelp and Gagome compete with one another along the coastline from Hakodate to Esan. We also examined the impacts of oceanographic environmental changes and atmospheric events on the availability of suitable sites and found that variations in the COC likely influenced scallop growth in winter and harvesting in April. In addition, we found that the warm water TWC significantly affected Japanese kelp and Gagome along the southern Hokkaido coastline, especially during the harvesting season (June-July). Extreme climate events, such as strong El Niño or AO impacts, may also negatively influence scallop and kelp aquaculture. And the results were consistent with production statistic data. Large-scale climate events should therefore be considered in management planning for scallop and kelp aquaculture in southern Hokkaido.

\section{Acknowledgments}

This work was supported by the "Hakodate Marine Bio Cluster Project" in the Regional Innovation Cluster Program (Global Type) from 2009 onward and a Grant-in-Aid for University and Society Collaboration from the Ministry of Education, Culture, Sports, Science and Technology (MEXT), Japan. Support was also provided by grants from the Project of the Bio-Oriented Technology Research Advancement Institution (NARO). 


\section{Author Contributions}

Professor Sei-Ichi Saitoh and Associate Professor Toru Hirawake provided advice and guidance. Satoshi Nakada provided 4D-VAR data and doctoral student Xun Zhang analyzed sea temperature-depth visualization maps.

\section{Conflicts of Interest}

The authors declare no conflict of interest.

\section{References}

1. Food and Agriculture Organization (FAO). The State of World Fisheries and Aquaculture 209; FAO: Rome, Italy, 2014.

2. De Silva, S.S.; Soto, D. Climate Change and Aquaculture: Potential Impacts, Adaptation and Mitigation. In Climate Change Implications for Fisheries and Aquaculture: Overview of Current Scientific Knowledge; Cochrane, C.K., de Young, D.S., Bahri, T., Eds.; FAO: Rome, Italy, 2009; pp. 151-212.

3. Marine Net Hokkaido, Search and aggregate statistics of the fishery catch from 1991 to 2012. Available online: http://www.fishexp.hro.or.jp/cont/marine/index.html (accessed on 9 January 2015).

4. Kirihara, S.; Nakamura, T.; Kon, N.; Fujita, D.; Notoya, M. Recent fluctuations in distribution and biomass of cold and warm temperature species of Laminarialean algae at Cape Ohma, northern Honshu, Japan. J. Appl. Phys. 2006, 18, 521-527.

5. Yan, H.M.; Kakuta, S.; Nishihara, M.; Sugi, M.; Adachi, Y.; Ohno, N.; Iwakura, Y.; Tsuji, N.M. Kjellmaniella. crassifolia Miyabe (Gagome) extract modulates intestinal and systemic immune responses. Biosci. Biotechnol. Biochem. 2011, 75, 2178-2183.

6. Kleinman, S.; Hatcher, B.G.; Scheibling, R.E.; Taylor, L.H.; Hennigar, A.W. Shell and Tissue Growth of Juvenile Sea Scallops (Placopecten. magellanicus) in Suspended and Bottom Culture in Lunenburg Bay, Nova Scotia. Aquaculture 1996, 142, 75-97.

7. Direct Factory Outlets (DFO). Assessment of the scallop fishery (Placopecten magellanicus) of the southern gulf of St. Lawrence. Available online: http://www.isdm-gdsi.gc.ca/csas-sccs/applications/ Publications/result-eng.asp? params $=0 \&$ series $=7 \&$ year=2011 (accessed on 10 January 2015).

8. Cultured Aquatic Species Information Programme (Laminaria japonica). Cultured Aquatic Species Information Programme. Available online: http://www.fao.org/fishery/culturedspecies/ Laminaria_japonica/en (accessed on 10 January 2015).

9. Ohtani, K. Studies on the change of the hydrographic conditions in the Funka Bay II. Characteristics of the water occupying the Funka Bay. Bull. Fac. Fish. Hokkaido Univ. 1971, 22, 58-66.

10. Tanno, T.; Kuroda, H.; Isoda, Y.; Aiki, T. Flow variations off Cape of Esan, northeast of Tsugaru Strait. Bull. Fac. Fish. Hokkaido Univ. 2005, 56, 33-41. (In Japanese)

11. Qiu, B. Large-scale variability in the midlatitude subtropical and subpolar North Pacific Ocean: Observations and causes. J. Phys. Oceanogr. 2002, 32, 353-375. 
12. Nishida, Y.; Kanomata, I.; Tanaka, I.; Sato, S.; Takahashi, S.; Matsubara, H. Seasonal and interannual variations of the volume transport through the Tsugaru Strait. Oceanogr. Jpn. 2003, 12, 487-499. (In Japanese)

13. Seager, B.R.; Harnik, N.; Robinson, W.A.; Kushnir, Y.; Ting, M.; Huang, H.P.; Velez, J. Mechanisms of Enso-Forcing of Hemi Spherically Symmetric Precipitation Variability. Quart. J. R. Meteor. Soc. 2005, 131, 1501-1527.

14. Zheng, J.; Liu, Q.Y.; Wang, C.Z.; Zheng, X.T. Impact of Heating Anomalies Associated with Rainfall Variations over the Indo-Western Pacific on Asian Atmospheric Circulation in Winter. Clim. Dyn. 2013, 40, 2023-2033.

15. Liu, Y.; Saitoh, S.-I.; Radiarta, I.N.; Hirawake, T. Spatiotemporal variations in suitable areas for Japanese scallop aquaculture in Dalian, China from 2003 to 2012. Aquaculture 2014, 422-423, $172-183$.

16. Bai, X.Z.; Wang, J.; Liu, Q.Z.; Wang, D.X.; Liu, Y. Severe Ice Conditions in the Bohai Sea, China, and Mild Ice Conditions in the Great Lakes during the 2009/10 Winter: Links to El Niño and a Strong Negative Arctic Oscillation. J. Clim. Appl. Meteor. 2011, 50, 1922-1935.

17. Kapetsky, J.M.; Anguilar-Manjarrez, J. Geographic Information Systems, Remote Sensing and Mapping for the Development and Management of Marine Aquaculture; FAO Fisheries Technical Paper; FAO: Rome, Italy, 2007; p. 125.

18. Radiarta, I.N.; Saitoh, S.-I.; Miyazono, A. GIS-based multi-criteria evaluationmodels for identifying suitable sites for Japanese scallop (Mizuhopecten yessoensis) aquaculture in Funka Bay, southwestern Hokkaido, Japan. Aquaculture 2008, 284, 127-135.

19. Radiarta, I.N.; Saitoh, S.-I. Biophysical models for Japanese scallop, Mizuhopeccten yessoensis, aquaculture site selection in Funka Bay, Hokkaido, Japan, using remotely sensed data and geographic information system. Aquacult. Int. 2009, 17, 403-419.

20. Saitoh, S.-I.; Mugo, R.; Radiarta, I.N.; Asaga, S.; Takahashi, F.; Hirawake, T.; Ishikawa, Y.; Awaji, T.; In, T.; Shima, S. Some operational uses of satellite remote sensing and marine GIS for sustainable fisheries and aquaculture. ICES J. Mar. Sci. 2011, 68, 687-695.

21. Liu, Y.; Saitoh, S.-I.; Radiarta, I.N.; Isada, T.; Hirawake, T.; Mizuta, H.; Yasui, H. Improvement of an aquaculture site-selection model for Japanese kelp (Saccharina. japonica) in southern Hokkaido, Japan: An application for the impacts of climate events. ICES J. Mar. Sci. 2013, 70, 1460-1470.

22. Liu, Y.; Saitoh, S.-I.; Igarashi, H.; Hirawake, T. The regional impacts of climate change on coastal environments and the aquaculture of Japanese scallops in northeast Asia: Case studies from Dalian, China and Funka Bay, Japan. Int. J. Remote Sens. 2014, 35, 4422-4440.

23. Ahn, Y.H.; Moon, J.E.; Gallegos, S. Development of suspended particulate matter algorithms for ocean color remote sensing. Korean J. Remote Sens. 2001, 17, 285-295.

24. Nakada, S.; Ishikawa, Y.; Awaji, T.; In, T.; Shima, S.; Nakayama, T.; Isada, T.; Saitoh, S.-I. Modeling runoff into a region of freshwater influence for improved ocean prediction: Application to Funka Bay. Hydrol. Res. Lett. 2012, 6, 47-52.

25. Ishikawa, Y.; Awaji, T.; Toyoda, T.; In, T.; Nishina, K.; Nakayama, T.; Shima, S.; Masuda, S. High-resolution synthetic monitoring by 4-dimensional variational data assimilation system in the northwestern North Pacific. J. Mar. Syst. 2009, 78, 237-248. 
26. Yamamote, H. Monthly Changes in the Occurrence and Growth of Kjellmaniella crassifolia Miyabe. Bull. Fac. Fish. Hokkaido Univ. 1986, 37, 165-170.

27. Ozaki, A.; Mizuta, H.; Yamamoto, H. Physiological differences between the nutrient uptakes of Kjellmaniella. crassifolia and Laminaria. japonica (Phaeophyceae). Fish. Sci. 2001, 67, 415-419.

28. Mizuta, H. Distribution of Laminaria. species in the coastal Oyashio region and their nutrient requirements. Bull. Coast. Oceanogr. 2003, 41, 33-38. (In Japanese)

29. Hirose, N.; Fukudome, K. Monitoring the Tsushima Warm Current improves seasonal prediction of the regional snowfall. Sci. Online Lett. Atmos. 2006, 2, 61-63.

30. Hirose, N.; Nishimura, K.; Yamamoto, M. Observational evidence of a warm ocean current preceding a winter teleconnection pattern in the northwestern Pacific. Geophys. Res. Lett. 2009, doi:10.1029/2009GL037448.

(C) 2015 by the authors; licensee MDPI, Basel, Switzerland. This article is an open access article distributed under the terms and conditions of the Creative Commons Attribution license (http://creativecommons.org/licenses/by/4.0/). 